\title{
REVIEW
}

\section{The age of biomedicine: current trends in traditional subjects}

\author{
Josef Berger \\ Faculty of Health and Social Studies, University of South Bohemia, České Budějovice, Czech Republic
}

Received $4^{\text {th }}$ January 2011.

Revised $17^{\text {th }}$ February 2011.

Published online $5^{\text {th }}$ April 2011.

\begin{abstract}
Summary
The earliest scientific journals on biomedicine began publication in the 50s and their authors addressed the application of biology to medicine. More recently, biochemistry and biomedical engineering questions have figured more prominently. This trend is discussed in a survey of the topics appearing in the Journal of Applied Biomedicine. Pharmacological and toxicological articles have been popular over the long term and the neurosciences, chronomedicine, molecular and cell biomedicine have also been very important. The role of computational biomedicine and nanomedicine has received increasing attention as has the part which applied biomedicine can play in the enhancement of the general economy.
\end{abstract}

Key words: cell biology; computer; molecular medicine; nanomedicine; neuroscience; pharmacology; toxicology

\section{INTRODUCTION}

Biomedicine is an interdisciplinary area connecting human medicine, veterinary medicine, biology and technology. It involves the study of (patho-) physiological processes using the methods of biology, chemistry and physics. Biomedical research is carried out from the particular perspective of devising new strategies for diagnosis and therapy.

In recent years, articles using the term 'biomedicine' have represented approximately eight per cent of the total number of articles using the more

Josef Berger, Department of Clinical and Preclinical Studies, Faculty of Health and Social Studies, University of South Bohemia, Emy Destinové, 37005 České Budějovice, Czech Republic

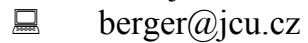

監 +420389037617 general term 'medicine' (ISI Web of Knowledge). This ratio seems to be stable: $7.04 \%$ in 2006 and $7.95 \%$ in 2010. Moreover, a large number of biomedical articles, is published in many journals dealing with cell and developmental biology, genetics, biochemistry, physiology, microbiology, preventive medicine, informatics, biotechnology, ethics and economics.

Applied biomedicine can also offer the prospect of an improvement in the economy (Mims 2010).

\section{DRUG AND POISON RESEARCH}

The growing number of high resolution structures of known and potential drugs targeting proteins is expected to have tremendous value for future drug discovery programs (Weigelt 2010). Herbal compounds such as phenolics, polyphenols, alkaloids, quinones, terpenoids, lectines and polypeptides have been shown to be very effective alternatives to 
antibiotics and other synthetic compounds (Citarasu 2010, De et al. 2010, Habib et al. 2010, Patočka and Jakl 2010).

New alternative models for toxicological safety tests of chemicals have been found to achieve faster, cheaper and more accurate preclinical prediction (Asami et al. 2010, Benigni et al. 2010, Berger 2010, Gadea and Garcia-Vazquez 2010). As toxicology leans towards the acquisition of knowledge of safety tests before the investigation of mechanisms, the evaluation of known drugs and poisons still predominates among recent studies (cf. Cabal et al. 2010, Pohanka et al. 2010, Soukup et al. 2010, Žd'árová Karasová et al. 2010).

Many drugs have been found among the membrane active compounds although in vitro screening has not been reliable. Membrane active proteins are important anti-bacterial agents (Rivas et al. 2010). Studies carried out on toxin structures, receptors, trafficking pathways and cellular targets might be exploited in cancer therapy and immunotherapy (Johannes and Römer 2010).

In anti-ageing medicine, the search for geroprotectors has been hopeful, particularly in the results of both natural and synthetic antioxidant studies on animals (Koltover 2010). No significant anti-ageing benefit has been documented in clinical studies but the arrangement of oxidative stress seems to be a good strategy for enhancing the clinical efficiency of anti-tumour drugs with low side effects (Sánchez et al. 2010).

\section{ENVIRONMENTAL MEDICINE}

Radiation risk has been frequently studied in addition to the potential toxic effects of the chemicals mentioned above. The KiKK study in Germany suggests that a higher child leukaemia incidence exists around nuclear power plants, although no links between levels of radiation and leukaemia risk have been found (Zölzer 2010). Haematopoietic cells may be considerably more radiosensitive in embryos/foetuses than in newborn babies (Fairlie 2010) but this hypothesis has not been confirmed precisely.

Stress often leads to the inhibition of major nuclear pathways, activation of DNA repair and dramatic changes in the organization and composition of the nucleolus (Boullon et al. 2010). The nucleolin is the major nucleolar protein and it is absolutely essential for cell proliferation, for the organization of the nucleolus and for transcription and processing of pre-rRNA (Medina et al. 2010).
DNA methylation and histone modification are the main epigenetic events that regulate nuclear processes and play an important role in the regulation of rRNA gene transcription (Bártová et al. 2010). Disorders in this process in response to environment, diet or pharmacological intervention contribute to pathophysiological states, including cancer (Link et al. 2010).

\section{COMPUTATIONAL MEDICINE}

Computers can support routine clinical decision making and can offer simulations - so called 'in-silico models' - in the framework of toxicology and environmental medicine. Recent computer base decision systems are frequently used to image segmentation and classification, feature construction and selection, signal processing (Soda et al. 2010), and prostate cancer treatment (Taylor et al. 2010) as well as in the diagnosis of several diseases.

Computational toxicology supports physiologically based pharmacokinetic and pharmacodynamic modelling, quantitative structure-activity relationship methods, and dose models (Rusyn and Daston 2010, Valerio 2010). In silico models have been developed for drug and vaccine screening (Berger 2010, Naven et al. 2010, Sung et al. 2010), cancers (Edelman et al. 2010), and studies of blood coagulation proteins (Villoutreix and Sperandio 2010).

\section{NEUROSCIENCES}

Neurosciences represent a very large area of biomedicine focusing on problems of both the function of the neural system and its degeneration. The activation of GnRH neurons leads to the attainment of reproductive capacity: endocrine glands and several genes are involved in the hypothalamic-hypophyseal-gonadal axis function which promotes the onset of the reproductive function during puberty (Meza-Herrera et al. 2010).

The most common cause of dementia in the elderly is Alzheimer's disease, likely systemic manifestations of which are neoplastic-like features, cell cycle dysfunction and impaired programmed cell death (de las Cuevas et al. 2010).

Acetylcholinesterase inhibitors may have neuroprotective effects slowing the progression of behavioural deterioration because acetylcholinesterases themselves could contribute to the neurodegenerative process (Nieoullon 2010). A 
significant effect of a later retirement age in delaying the age of onset of Alzheimer disease has been noted in males (Lupton et al. 2010).

\section{CHRONOMEDICINE}

The biological clock has evolved so that organisms can adapt to our planet's rotation in order to anticipate the coming day or night as well as unfavourable seasons (Giudice et al. 2010, Jolma et al. 2010).

Impaired neurodevelopment is associated with the hypotension in infancy and more pronounced circadian variation in transcutaneous $\mathrm{pO}_{2}$ (Cornélissen et al. 2010b). It is well-known that many immune characteristics are altered in old human subjects.

This phenomenon is the consequence of the age-associated decrease in growth hormone secretion and insulin-like growth factor production (Mazzoccoli et al. 2010) as variations in this axis may be responsible for altered integration between the neuro-endocrine and immune system.

Circadian vascular characteristics are sensitive markers of loads, including the rest-activity schedule (Cornélissen et al. 2010a). Our awareness of blood characteristics the sampling for which should be strictly standardized with regard to the time of the day, is still increasing in both human and veterinary medicine (Berger 2008, Giannetto et al. 2010).

\section{MOLECULAR AND CELL BIOLOGY}

The gene for endoglin, activin receptor-like kinase (ALK1) and Smad4 proteins is mutated in most patients with hereditary haemorrhagic telangiectasia which has no known cure. These three proteins are involved in the signalling pathway of the transforming growth factor (TGF)- $\beta$ superfamily. Research into their regulatory roles is, therefore, needed to find an effective drug (Bernabéu et al. 2010).

Among therapeutic strategies to combat multidrug-resistant pneumococcal infections, the use of purified phage- or bacteria-encoded CWHs both in vitro and in animal models is under investigation (García et al. 2010). The growing structural and functional information on toxin-antitoxin systems opens important avenues to the exploration of their biomedical and biotechnological implications (Díaz-Orejas et al. 2010).
Both the nasal and tonsillar mucosa are exposed to massive incursions of pathological microorganisms present in inhaled air and swallowed with food. One of the mechanisms known to prevent an invasion of pathogens is an endogenous synthesis of antimicrobial peptides, which include human $\beta$-defensins $-1,2$, and 3 . Very low - nearly nil incidence of human $\beta$-defensins- 1,2 , and 3 was detected in the nasal polyps with positive Staphylococcus aureus (Pácová et al. 2010).

A well-established trend in modern biological sciences is an overwhelming pressure on scientists to work on problems and model systems with obvious clinical, technological or environmental interest. Studies of Rep-type plasmidic proteins reveal that plasmid DNA replication is relevant for settling the bases of a minimalist bacterial model to tackle transmissible amyloid proteinopathies, and are a valuable tool for bottom-up synthetic biology (Giraldo and Fernández-Tresguerres 2010).

\section{BIOENGINEERING}

Clinical studies benefit from newly developed biomaterials for therapy and diagnostics ( $\mathrm{Gu}$ et al. 2010) and also for medical instruments (Lendlein et al. 2010). The influence of polymer-based devices on cell surfaces is evaluated at the final product level as well as the polymers used in regenerative medicine (Scharnagl et al. 2010).

Plasma treated materials have an important role in medicine and are undergoing fast development (Cheruthazhekatt et al. 2010). Nanomedicine uses tools and devices of size 1 to $100 \mathrm{~nm}$ and has an increasing impact on diagnostics and pharmacology (Teli et al. 2010), but nevertheless, the undesired adverse effects of nanotechnological products as well as ethical aspects (Bowen 2010) have to be solved.

\section{REFERENCES}

Asami Y, Horie R, Hamamoto H, Sekimizu K. Use of silkworms for identification of drug candidates having appropriate pharmacokinetics from plant sources. BMC Pharmacol. 10, art. no. 7, 2010.

Bártová E, Harničarová Horáková A, Uhlírová R, Raška I, Galiová G, Orlova D, Kozubek S. Structure and epigenetics of nucleoli in comparison with non-nucleolar compartments. J Histochem Cytochem. 58: 391-403, 2010. 
Benigni R, Bossa C, Tcheremenskaia O, Giuliani A. Alternatives to the carcinogenicity bioassay: in silico methods, and the in vitro and in vivo mutagenicity assays. Expert Opin Drug Metab Toxicol. 6: 809-819, 2010.

Berger J. A two-clock model of circadian timing in the immune system of mammals. Pathol Biol. 56: 286-291, 2008.

Berger J. Alternative haematotoxicological testing. J Appl Biomed. 8: 19-22, 2010.

Bernabéu C, Blanco FJ, Langa C, Garrido-Martin EM, Botella LM. Involvement of the TGF- $\beta$ superfamily signalling pathway in hereditary haemorrhagic telangiectasia. J Appl Biomed. 8: 169-177, 2010.

Boulon S, Westman BJ, Hutten S, Boisvert F-M, Lamond AI. The nucleolus under stress. Mol Cell. 40(SI): 216-227, 2010.

Bowen WR. Nanotechnology: the ethical challenge. Nanotechnol Perc. 6: 95-103, 2010.

Cabal J, Míčová J, Kuča K. Kinetics of hydrolysis of organophosphate soman by cationic surfactant Resamin AE. J Appl Biomed. 8: 111-116, 2010.

Citarasu T. Herbal biomedicine: a new opportunity for aquaculture industry. Aquacult Int. 18: 403-414, 2010

Cheruthazhekatt S, Černák M, Slavíček P, Havel J. Gas plasmas and plasma modified materials in medicine. J Appl Biomed. 8: 55-66, 2010.

Cornélissen G, Galli C, Halberg F De Meester F, Risé P, Wilczynska-Kwiatek A, Singh R, Guillaume F. Circadian time structure of fatty acids and vascular monitoring. J Appl Biomed. 8: 93-109, 2010a.

Cornélissen G, Halberg F, Syutkina EV, Yatsyk, GV, Masalov AV, Schwartzkopff O, Johnson D. Assessing variability in neonatal blood pressure, notably in hypotension. J Appl Biomed. 8: 209-211, 2010b.

De D, Chatterjee K, Ali KM, Mandal S, Barik B, Ghosh D. Antidiabetic and antioxidative effects of hydro-methanolic extract of sepals of Salmalia malabarica in streptozotocin induced diabetic rats. J Appl Biomed. 8: 23-33, 2010.

de las Cuevas ND, Muñoz U, Bartolomé F, Esteras N, Alquezar C, Martín-Requero A. Cell cycle and Alzheimer's disease: studies in non-neuronal cells. J Appl Biomed. 8: 121-130, 2010.

Díaz-Orejas R, Diago-Navarro E, Arriaga AMH, López-Villarejo J, Lemonnier M, MorenoCórdoba I, Nieto C, Espinosa M. Bacterial toxin-antitoxin systems targeting translation. J Appl Biomed. 8: 179-188, 2010.

Edelman LB, Eddy JA, Price ND. In silico models of cancer. Wiley Interdiscip Rev Syst Biol Med. 2: 438-459, 2010.
Fairlie I. Hypothesis to explain childhood cancer near nuclear power plants. Int J Occup Environm Hlth. 16: 341-350, 2010.

Gadea J, García-Vázquez FA. Applications of transgenic pigs in biomedicine and animal production. Inf Tec Econ Agr. 106: 30-45, 2010.

García P, Moscoso M, Rodríguez-Cerrato V, Yuste J, García E. Streptococcus pneumoniae: from molecular biology to host-pathogen interactions. J Appl Biomed. 8: 131-140, 2010.

Giannetto C, Casella S, Fazio F, Messina V, Piccione G. Circadian variations in biochemical markers of bone metabolism in horse of different age. J Appl Biomed. 8: 73-79, 2010.

Giraldo R, Fernández-Tresguerres ME. Voyage of RepA protein from plasmid DNA replication through amyloid aggregation towards synthetic biology. J Appl Biomed. 8: 151-158, 2010.

Giudice A, Caraglia M, Marra M, Montella M, Maurea N, Abbruzzese A, Arra C. Circadian rhythms, adrenergic hormones and trafficking of hematopoietic stem cells. Expert Opin Ther Targets. 14: 567-575, 2010.

Gu ZW, Luo K, She WC, Wu Y, He B. New-generation biomedical materials: Peptide dendrimers and their application in biomedicine. Sci China Chem. 53: 458-478, 2010.

Habib MR, Aziz MA, Karim MR. Inhibition of Ehrlich's ascites carcinoma by ethyl acetate extract from the flower of Calotropis gigantea $\mathrm{L}$. mice. J Appl Biomed. 8: 47-54, 2010.

Johannes L, Römer W. Shiga toxins - from cell biology to biomedical applications. Nature Rev Microbiol. 8: 105-116, 2010.

Jolma IW, Laerum OD, Lillo C, Ruoff P. Circadian oscillators in eukaryotes. Wiley Interdiscipl Rev Syst Biol Med. 2: 533-549, 2010.

Koltover VK. Antioxidant biomedicine: from free radical chemistry to systems biology mechanisms. Russ Chem Bull. 59: 37-42, 2010.

Lendlein A, Rehahn M, Buchmeiser MR, Haag R. Polymers in biomedicine and electronics. Macromol Rapid Commun. 31(SI): 1487-1491, 2010.

Link A, Balaguer F, Goel A. Cancer chemoprevention by dietary polyphenols: promising role for epigenetics. Biochem Pharmacol. 80: 1771-1792, 2010.

Lupton MK, Stahl D, Archer N, Foy C, Poppe M, Lovestone S, Hollingworth P, Williams J, Owen MJ, Dowzell K, Abraham R, Sims R, Brayne C, Rubinstein D, Gill M, Lawlor B, Lynch A, Powell JF, John F. Education, occupation and retirement age effects on the age of onset of Alzheimer's disease. Int J Geriat Psych. 25: 30-36, 2010. 
Mazzoccoli G, Giuliani F, Inglese M, Marzulli N, Dagostino MP, De Cata A, Greco A, Carughi S, Tarquini R. Chronobiologic study of the GH-IGF1 axis and the ageing immune system. J Appl Biomed. 8: 213-226, 2010.

Medina FJ, González-Camacho F, Manzano AI, Manrique A, Herranz R: Nucleolin, a major conserved multifunctional nucleolar phosphoprotein of proliferating cells. J Appl Biomed. 8: 141-150, 2010.

Meza-Herrera CA, Veliz-Deras FG, Wurzinger M, López-Ariza B, Arellano-Rodriguez G, Rodriguez-Martinez R. The kiss-1-kisspeptingpr54 complex: a critical modulator of $\mathrm{GnRH}$ neurons during pubertal activation. J Appl Biomed. 8: 1-9, 2010.

Mims C. Sunshine biomedicine. Nature Med. 16: 1066-1067, 2010.

Naven RT, Louise-May S, Greene N. The computational prediction of genotoxicity. Expert Opin Drug Metab Toxicol. 6: 797-807, 2010.

Nieoullon A. Acetylcholinesterase inhibitors in Alzheimer's disease: Further comments on their mechanisms of action and therapeutic consequences. Psychol Neuropsych Vieill. 8: 123-131, 2010.

Pácová H, Astl J, Martínek J. The incidence of $\beta$-defensin-1, 2, 3 in human healthy and chronically inflamed nasal and tonsillar mucosa. J Appl Biomed. 8: 81-86, 2010.

Patočka J, Jakl J. Biomedically relevant chemical constituents of Valeriana officinalis. J Appl Biomed. 8: 11-18, 2010.

Pohanka M, Vlček V, Kuča K, Bandouchová H, Pikula J. Pesticide sorption in typical Central European soils evaluated using a photometric microplate assay based on acetylcholinesterase inhibition. J Appl Biomed. 8: 41-46, 2010.

Rivas L, Luque-Ortega JR, Fernández-Reyes M, Andreu D. Membrane-active peptides as antiinfectious agents. J Appl Biomed. 8: 159-167, 2010.

Rusyn I, Daston GP. Computational toxicology: Realizing the promise of the toxicity testing in the $21^{\text {st }}$ century. Environm Hlth Persp. 118: 1047-1050, 2010.
Sánchez Y, Amrán D, de Blas E, Aller P. Arsenic trioxide as an anti-tumour agent: mechanisms of action and strategies of sensitization. J Appl Biomed. 8: 199-208, 2010.

Scharnagl N, Lee S, Hiebl B, Sisson A, Lendlein A. Design principles for polymers as substratum for adherent cells. J Mat Chem. 20: 8789-8802, 2010.

Soda P, Pechenizkiy M, Tortorella F, Tsymbal A. Knowledge discovery and computer-based decision support in biomedicine. Art Intell Med. 50(SI): 1-2, 2010.

Soukup O, Holas O, Binder J, Killy K, Tobin G, Jun D, Fusek J, Kuča K. The effect of trimedoxime on acetylcholinesterase and on the cholinergic system of the rat bladder. J Appl Biomed. 8: 87-92, 2010.

Sung JH, Esch MB, Shuler ML. Integration of in silico and in vitro platforms for pharmacokinetic-pharmacodynamic modeling, Expert Opin Drug Metab Toxicol. 6: 1063-1081, 2010.

Taylor KL, Davis KM, Lamond T, Williams RM, Schwartz MD, Lawrence W, Feng SB, Brink S, Birney A, Lynch J, Regan J, Dritschilo A. Use and evaluation of a CD-ROM-based decision aid for prostate cancer treatment decisions. Behav Med. 36: 130-140, 2010.

Teli MK, Mutalik S, Rajanikant GK. Nanotechnology and nanomedicine going small means aiming big. Curr Pharm Design. 16: 1882-1992, 2010.

Valerio Jr., LG. Computational science in drug metabolism and toxicology. Expert Opin Drug Metab Toxicol. 6: 781-784, 2010.

Villoutreix BO, Sperandio O. In silico studies of blood coagulation proteins: from mosaic proteases to nonenzymatic cofactor inhibitors. Curr Opin Struct Biol. 20: 168-179, 2010.

Weigelt J. Structural genomics-impact on biomedicine and drug discovery. Exp Cell Res. 316: 1332-1338, 2010.

Zölzer F. Childhood leukaemia in the vicinity of German nuclear power plants - some missing links. J Appl Biomed. 8: 67-72, 2010.

Žd'árová Karasová J, Stodůlka $\mathrm{P}$, Kuča K. In vitro screening of blood-brain barrier penetration of clinically used acetylcholinesterase reactivators. J Appl Biomed. 8: 35-40, 2010. 